\title{
Sensitivity of simulated climate to latitudinal distribution of solar insolation reduction in solar radiation management
}

\author{
A. Modak and G. Bala \\ Divecha Centre for Climate Change \& Centre for Atmospheric and Oceanic Sciences, Indian Institute of Science, Bangalore, \\ 560012 , India
}

Correspondence to: A. Modak (amatcaos@caos.iisc.ernet.in)

Received: 15 July 2013 - Published in Atmos. Chem. Phys. Discuss.: 1 October 2013

Revised: 13 June 2014 - Accepted: 23 June 2014 - Published: 5 August 2014

\begin{abstract}
Solar radiation management (SRM) geoengineering has been proposed as a potential option to counteract climate change. We perform a set of idealized geoengineering simulations using Community Atmosphere Model version 3.1 developed at the National Center for Atmospheric Research to investigate the global hydrological implications of varying the latitudinal distribution of solar insolation reduction in SRM methods. To reduce the solar insolation we have prescribed sulfate aerosols in the stratosphere. The radiative forcing in the geoengineering simulations is the net forcing from a doubling of $\mathrm{CO}_{2}$ and the prescribed stratospheric aerosols. We find that for a fixed total mass of sulfate aerosols (12.6 Mt of $\mathrm{SO}_{4}$ ), relative to a uniform distribution which nearly offsets changes in global mean temperature from a doubling of $\mathrm{CO}_{2}$, global mean radiative forcing is larger when aerosol concentration is maximum at the poles leading to a warmer global mean climate and consequently an intensified hydrological cycle. Opposite changes are simulated when aerosol concentration is maximized in the tropics. We obtain a range of $1 \mathrm{~K}$ in global mean temperature and $3 \%$ in precipitation changes by varying the distribution pattern in our simulations: this range is about $50 \%$ of the climate change from a doubling of $\mathrm{CO}_{2}$. Hence, our study demonstrates that a range of global mean climate states, determined by the global mean radiative forcing, are possible for a fixed total amount of aerosols but with differing latitudinal distribution. However, it is important to note that this is an idealized study and thus not all important realistic climate processes are modeled.
\end{abstract}

\section{Introduction}

Atmospheric concentrations of the greenhouse gases (GHGs) such as carbon dioxide $\left(\mathrm{CO}_{2}\right)$, methane $\left(\mathrm{CH}_{4}\right)$ and nitrous oxide $\left(\mathrm{N}_{2} \mathrm{O}\right)$ have been increasing since pre-industrial periods primarily because of fossil fuel use and land-use change (IPCC, 2007). Their increase has the potential to cause long term climate change by altering the planetary radiation budget. To moderate future climate change and its impacts, several geoengineering proposals have been made recently. By definition, geoengineering is an intentional large-scale manipulation of the environment, particularly intended to counteract the undesired consequences of anthropogenic climate change (Keith, 2000).

Proposed geoengineering methods are classified into two main groups: solar radiation management (SRM) methods and carbon dioxide removal (CDR) methods (Shepherd et al., 2009). In the first approach, the amount of solar absorption by the planet is reduced by artificially enhancing the planetary albedo so that the reduced insolation compensates the radiative forcing due to rising GHGs. Some proposed methods are injecting sulfate aerosols in the stratosphere (Budkyo, 1982; Crutzen, 2006; Wigley, 2006) and placing space-based sun shields in between the Sun and the Earth (Early, 1989). Other SRM methods include marine cloud brightening and enhancement of land/ocean surface albedo. CDR methods propose to accelerate the removal of $\mathrm{CO}_{2}$ from the atmosphere and thus they deal with the root cause of global warming (Shepherd et al., 2009).

Past climate modeling studies have modeled the effects of space-based SRM methods by reducing the solar constant (Govindasamy and Caldeira, 2000; Matthews and Caldeira, 2007; Caldeira and Wood, 2008; Lunt et al., 2008) 
or modeled the effects of stratospheric aerosol methods (Robock et al., 2008; Rasch et al., 2008a; Rasch et al., 2008b; Heckendorn et al., 2009; Jones et al., 2010). It has been shown (e.g., Bala et al., 2008) that SRM geoengineering would lead to a weakening of the global water cycle when the global mean temperature change is offset exactly. A recent study (Tilmes et al., 2013) using 12 models from the Geoengineering Model Intercomparison Project (GeoMIP) confirms this weakening of the hydrological cycle under a multi-model framework. Further, it has been shown (Robock et al., 2008; Ricke et al., 2010; Tilmes et al., 2013) that the level of compensation will vary with residual changes larger in some regions than others. Therefore, some recent studies (Ban-Weiss and Caldeira, 2010; MacMartin et al., 2012) determine an optimal reduction in solar radiation in both space and time so that the geoengineered world is more similar to the control climate while other studies (Irvine et al., 2010; Ricke et al., 2010) analyze the effect of different levels of uniform SRM forcing on regional climate response. BanWeiss and Caldeira (2010) vary both the amount and the latitudinal distribution of aerosols to offset either the zonally averaged changes in surface temperature or the water budget. However, a simple and clear understanding of the effects of systematically varying the latitudinal distribution of aerosols and hence solar insolation reduction (e.g., more concentration in the tropics or high latitudes) on the hydrological cycle and surface temperature is lacking. In this study, we perform multiple idealized SRM geoengineering simulations with constant total amount of sulfate aerosols but with systematically varying the latitudinal distribution.

We caution that our simulations are highly idealized and they are not meant to represent realistic latitudinal distribution of aerosols in geoengineering scenarios and may not be technologically achievable. Rather, they are designed to elucidate the fundamental properties of the climate system when the latitudinal distribution of aerosols and hence solar insolation reduction is systematically altered. We believe that our study should be considered as complementary to a previous work (Ban-Weiss and Caldeira, 2010), because not only we vary the latitudinal distribution of aerosols but we also provide a constraint by fixing the total amount of aerosols which facilitates a clear insight on the effects of varying the latitudinal distribution of aerosols.

\section{Model and experiments}

We used the atmospheric general circulation model, CAM3.1 (Community Atmosphere Model version 3.1) developed at the National Center for Atmospheric Research (NCAR) (Collins et al., 2004). It is coupled to the land model CLM3.0 (Community Land Model version 3.0) and to a slab ocean model (SOM) with a thermodynamic sea ice model to represent the interactions with the ocean and sea ice components of the climate system. The model can be also configured with prescribed sea surface temperature and sea ice fraction. The horizontal resolution is $2^{\circ}$ latitude and $2.5^{\circ}$ longitude and the model has 26 vertical levels and the top of the model (TOM) is at $3 \mathrm{hPa}$.

We performed two sets of simulations: (1) fixed-SST (sea surface temperature) simulations to estimate the radiative forcing which is measured as the net radiative flux change at the top of the atmosphere (Hansen et al., 1997). This method allows the rapid adjustment of the atmosphere and land components before radiative forcing is evaluated. (2) The other set includes the SOM simulations to study the climate change. For both sets of simulations, fixed-SST and SOM, we performed 12 cases: a control $\left(1 \times \mathrm{CO}_{2}\right)$, doubled $\mathrm{CO}_{2}$ climate $\left(2 \times \mathrm{CO}_{2}\right)$ and ten geoengineering simulations each with differing latitudinal distribution of sulfate aerosol concentrations but with fixed total amount. The concentration of atmospheric $\mathrm{CO}_{2}$ in $1 \times \mathrm{CO}_{2}$ is $390 \mathrm{ppm}$ and is $780 \mathrm{ppm}$ in $2 \times \mathrm{CO}_{2}$ and geoengineering simulations. The concentrations of other greenhouse gases are kept constant in all simulations. The background sulfate aerosol amount in this version of the model is $1.38 \mathrm{Mt} \mathrm{SO}_{4}$. The fixed-SST simulations lasted for 30 years and the last 20 years are used to calculate the radiative forcing. The SOM simulations lasted for 60 years and the last 30 years are used for climate change analysis since all SOM simulations reach a near-equilibrium climate state in approximately 25 years.

As in Ban-Weiss and Caldeira (2010), the additional sulfate aerosols are prescribed in the geoengineering cases (Table 1, Fig. 1a) and hence it is not transported around. However, in contrast to Ban-Weiss and Caldeira (2010), we introduce the constraint that the total amount of aerosol is constant $\left(12.6 \mathrm{Mt} \mathrm{SO}_{4}\right)$ while latitudinal distributions are varied. Since aerosols are prescribed at TOM, the effect is essentially equivalent to making latitudinal changes to the solar constant. Sulfate aerosol particle size is prescribed and is assumed to be log-normally distributed with dry median radius $\approx 0.05 \mu \mathrm{m}$ and geometric standard deviation $\approx 2.0$ (as used in the "small particle" geoengineering scenario in a previous study (Rasch et al., 2008b)). The indirect aerosol effects are not modeled and aerosol loadings for other species like sea-salt, soil dust, black and organic carbon are unchanged in each of the simulations.

Besides a simulation with uniform aerosol concentration, our geoengineering simulations can be grouped into two categories: (1) Three Tropics simulations with maximum aerosol concentrations at the equator and (2) six Polar cases with maximum concentrations at the poles. The latitudinal distribution of the stratospheric sulfate aerosol concentration are developed using the expression:

$Q(\varphi)=a+b \cos (\varphi)$,

where $Q$ is the concentration of the additional mass of sulfate aerosols, $a$ and $b \cos (\varphi)$ are the uniform and non-uniform components of the distributions and $\varphi$ represents the latitude. 
Table 1. Description of different geoengineering experiments. Total additional mass is $12.6 \mathrm{Mt} \mathrm{SO}_{4}$ in all the geoengineering simulations but the distribution varies.

\begin{tabular}{lccccc}
\hline $\begin{array}{l}\text { Name of the } \\
\text { experiments }\end{array}$ & $\mathrm{a}\left(\mathrm{mg} \mathrm{m}^{-2}\right)$ & $\mathrm{b}\left(\mathrm{mg} \mathrm{m}^{-2}\right)$ & $\begin{array}{c}\text { Total mass from } \\
\text { uniform component }(\mathrm{Mt})\end{array}$ & $\begin{array}{c}\text { Total mass from } \\
\text { non-uniform component (Mt) }\end{array}$ & $\begin{array}{c}\text { Total mass } \\
(\mathrm{Mt})\end{array}$ \\
\hline Uniform & 24.70 & - & 12.60 & - & 12.60 \\
Polar1 & 23.52 & 3.19 & 12.00 & 0.60 & 12.60 \\
Polar2 & 21.56 & 8.55 & 11.00 & 1.60 & 12.60 \\
Polar3 & 19.60 & 13.89 & 10.00 & 2.60 & 12.60 \\
Polar4 & 17.64 & 19.22 & 9.00 & 3.60 & 12.60 \\
Polar5 & 15.68 & 24.56 & 8.00 & 4.60 & 12.60 \\
Polar6 & 13.72 & 29.90 & 7.00 & 5.60 & 12.60 \\
Tropics1 & 26.66 & -5.34 & 13.60 & -1.00 & 12.60 \\
Tropics2 & 28.62 & -10.67 & 14.60 & -2.00 & 12.60 \\
Tropics3 & 30.58 & -16.02 & 15.60 & -3.00 & 12.60 \\
\hline
\end{tabular}

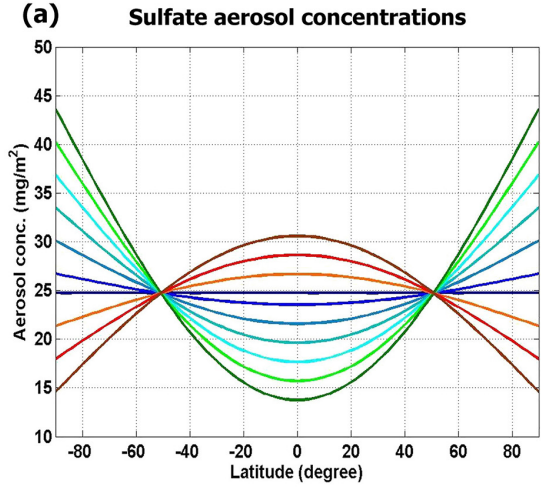

(c) Radiative forcing vs

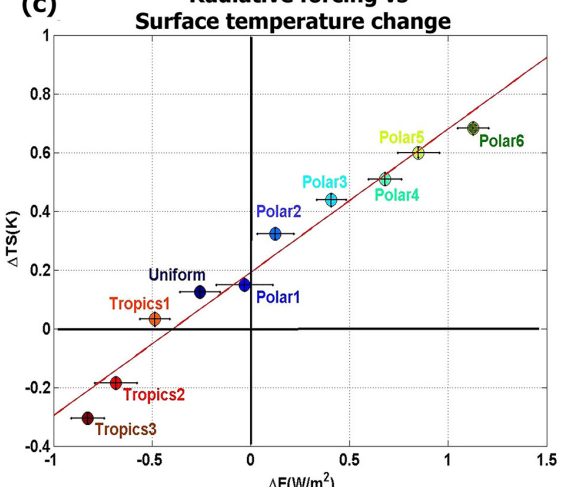

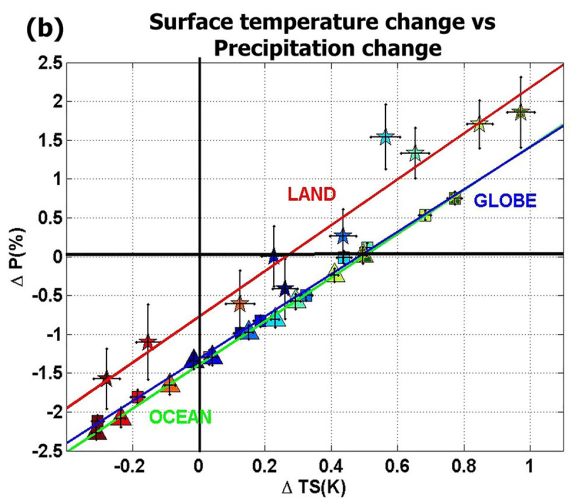

(d)
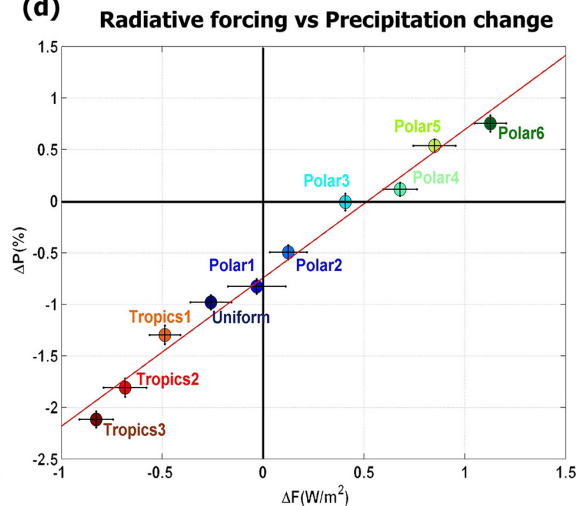

$\Delta \mathrm{F}\left(\mathrm{W} / \mathrm{m}^{2}\right)$

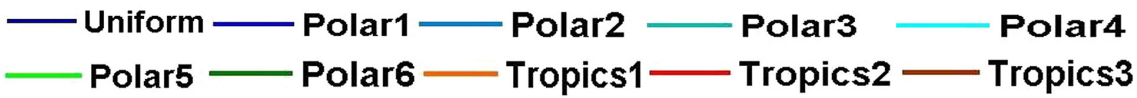

Figure 1. (a) Latitudinal profiles of sulfate aerosol concentration in the SRM geoengineering experiments. Polar1-6 have maximum concentration over the poles and Tropics1-3 have maximum at the equator. (b) Surface temperature change (K) vs precipitation change (\%) relative to the $1 \times \mathrm{CO}_{2}$ case from slab ocean simulations (global mean values - squares, land mean values - stars, ocean mean values - triangles). There is warming in all Polar cases relative to the Uniform case and a concomitant increase in precipitation. Opposite is the case for Tropics cases. None of the regression lines pass through origin; temperature and precipitation cannot be offset simultaneously. In the case of land and ocean, $\Delta \mathrm{TS}$ and $\Delta \mathrm{P}$ represent the averages over the respective domain. (c) Radiative forcing (RF) vs surface temperature change. Polar cases have larger forcing relative to the Uniform case and hence are warmer while opposite is true for Tropics cases. (d) Radiative forcing vs \% precipitation change. Precipitation increases with residual RF (i.e. with increase in polar weighting) while decreases with increase in tropical weighting. In (b), (c) and (d), the horizontal and vertical bars represent the standard error of the respective variables which are calculated from the last 30 years of 60-year SOM simulations, while in the case of radiative forcing it is calculated from the last 20 years of 30 -year fixed-SST simulations. 
Both $a$ and $b$ are varied to obtain various distributions of concentrations (Table 1, Fig. 1a). However, when $Q$ is integrated over the sphere, the result is $12.6 \mathrm{Mt}$ in all cases. Our choice of $12.6 \mathrm{Mt}$ for $Q$ is dictated by the uniform distribution case which had near-zero global mean temperature change relative to the control case. In each of the geoengineering simulations aerosol mass is added to the model background concentration at the TOM as was done in a recent study (BanWeiss and Caldeira, 2010). An experiment where the same total mass $(12.6 \mathrm{Mt})$ of aerosol is distributed uniformly over the globe between $61 \mathrm{hPa}$ to $9.8 \mathrm{hPa}(15-30 \mathrm{~km})$ with a maximum at $30 \mathrm{hPa}(22 \mathrm{~km})$ showed that the radiative forcing is nearly the same as in our uniform distribution geoengineering case and hence the main conclusions reached in this study are unlikely to be altered by distributing the aerosols within the stratosphere.

\section{Results}

\subsection{Global mean temperature and precipitation response}

Unless otherwise specified the changes discussed here are with respect to the $1 \times \mathrm{CO}_{2}$ case. We find that the radiative forcing for doubling the atmospheric $\mathrm{CO}_{2}\left(2 \times \mathrm{CO}_{2}\right)$ to be $3.5 \mathrm{~W} \mathrm{~m}^{-2}$ while the global mean surface temperature rise is about $2.1 \mathrm{~K}$ and the precipitation increase is about $4.3 \%$ (i.e. $\approx 2 \% \mathrm{~K}^{-1}$ ) in agreement with the previous studies using the same model (Rasch et al., 2008b; Bala et al., 2009). The slopes in Fig. 1c and d indicate a climate sensitivity of $0.53 \mathrm{~K}_{\text {per }} \mathrm{Wm}^{-2}$ and precipitation sensitivity (\% change in precipitation for unit change in radiative forcing) of $1.5 \%$ per $\mathrm{Wm}^{-2}$ respectively, values that are similar to Bala et al. (2009).

The slight warming in the geoengineering case where forcing is close to zero (the case Polar1 in Fig. 1c) is because of the $\mathrm{CO}_{2}$ physiological forcing (Betts et al., 2007; Cao et al., 2010) which is not counteracted by a decrease in solar flux. $\mathrm{CO}_{2}$-physiological forcing refers to the direct physiological response of plants to elevated $\mathrm{CO}_{2}$ : the plant stomata open less widely and thus decrease the canopy transpiration which in turn reduces evapotranspiration and causes surface warming. Therefore, in the zero radiative forcing case (Polar1) where $\mathrm{CO}_{2}$ radiative forcing is countered by the reduction in solar radiation, the $\mathrm{CO}_{2}$-physiological forcing could lead to a slight warming. It is also likely that the slight non uniform distribution of aerosols in Polar1 case could partly contribute to this warming.

In agreement with past studies (e.g., Lunt et al., 2008; Bala et al., 2008; Tilmes et al. 2013), we find that in the geoengineering scenario with uniform distribution of aerosol there is a decline in precipitation though there is a near cancellation of surface temperature change (Fig. 1b). This occurs because of the differing fast response (changes that occur before global mean surface temperature change) in precipitation for solar and $\mathrm{CO}_{2}$-forcing (Allen and Ingram, 2002; Bala et al., 2008, 2009; Andrews et al., 2009): long-wave absorption by $\mathrm{CO}_{2}$ in the atmosphere can contribute to increased vertical stability and suppress precipitation but this fast response mechanism is nearly absent for solar forcing because the atmosphere is nearly transparent to solar radiation. However, since the slow response (changes that are associated with global mean surface temperature change) is same for $\mathrm{CO}_{2}$ and solar forcings (Bala et al. 2010), the total changes in rainfall are larger to solar forcing than to equivalent $\mathrm{CO}_{2}$ forcing. Because of this differing hydrological sensitivity to solar and $\mathrm{CO}_{2}$ forcing, insolation reductions (in geoengineering scenarios) sufficient to offset the entirety of global-scale temperature increases would lead to a decrease in global mean precipitation. This suppression of precipitation is simulated in all geoengineering simulations (the regression line does not pass through the origin in Fig. 1b).

Our geoengineering simulations with varying aerosol distributions indicate a linear relationship between the global mean surface temperature change and the precipitation change (Fig. 1b). The regression lines do not pass through the origin which implies that none of the distribution can offset global mean temperature and precipitation simultaneously. Though the total amount of aerosols in each of the geoengineering simulation is fixed, we obtain a range of $1 \mathrm{~K}$ (residual cooling of $0.3 \mathrm{~K}$ for the Tropics 3 case to residual warming of $0.7 \mathrm{~K}$ for the Polar6 case) in global mean temperature and $3 \%$ (residual drying of $2 \%$ for Tropics 3 case to residual increase of $1 \%$ for the Polar6 case) in precipitation changes which are about $50 \%$ or more of the changes that result from doubling of $\mathrm{CO}_{2}$. This indicates that a range of climate states are possible for a constant amount of aerosols.

As the polar maximum of the aerosol concentration increases the global mean temperature increases with concomitant increase in global mean precipitation as implied by the linear relationship in Fig. 1b. One of the polar maximum SRM simulations (Polar3) almost offsets the changes in global mean precipitation but it has a residual warming of $0.4^{\circ} \mathrm{C}$. Our results are broadly in agreement with other modeling studies: in an Arctic geoengineering study (Caldeira and Wood, 2008) with reduced solar constant only over arctic, residual global mean warming and enhancements of global precipitation are found.

In contrast, as the magnitude of the tropical maximum concentration increases both global mean temperature and precipitation decreases. One of the Tropics cases (Tropics1) where the temperature change is nearly zero shows a reduction in the global mean precipitation. Our Tropics simulations can be qualitatively compared to the Mount Pinatubo $\left(15^{\circ} \mathrm{N}\right)$ eruption in 1991 because the distribution of aerosols in Tropics simulations has reasonable resemblance to the distribution of aerosols after a few weeks of the eruption (the volcanic aerosols occupied a latitude band of $20^{\circ} \mathrm{S}$ to $30^{\circ} \mathrm{N}$; McCormick et al., 1995). Further, similarly to the global 


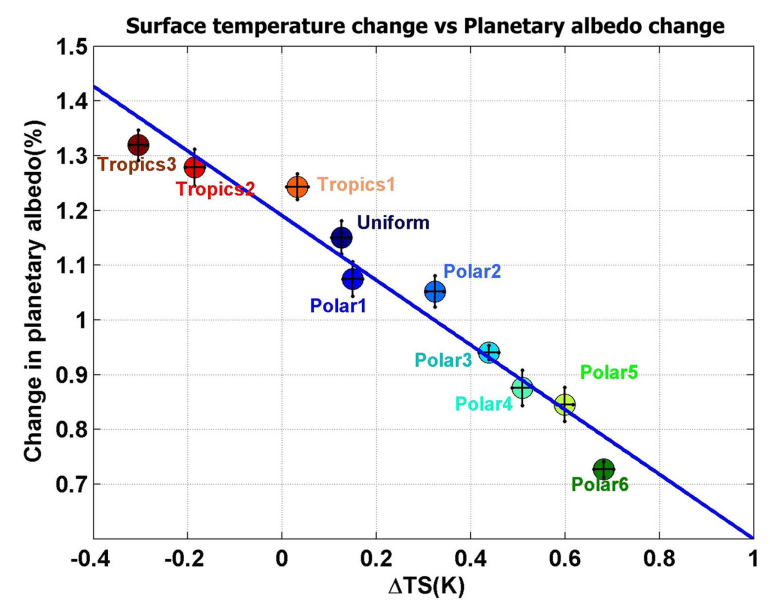

Figure 2. Change in planetary albedo in fixed-SST vs surface temperature change in slab ocean geoengineering simulations. The radiative forcing associated with albedo changes drive the temperature changes. Polar cases have lower albedo changes relative to the Uniform case and hence are warmer and wetter while opposite is true for Tropics cases. The horizontal and vertical bars represent the standard error of the respective variables; temperature standard errors are calculated from the last 30 years of 60-year SOM simulations while albedo standard errors are calculated from the last 20 years of 30-year fixed-SST simulations.

mean precipitation and temperature decline after the eruption (Parker et al. 1996; Trenberth and Dai, 2007), we also simulate a reduction of global mean temperature and precipitation in our Tropics simulations (except in Tropics1 case). Interestingly, we find that in none of the geoengineering scenarios considered in this study, changes in global mean surface temperature and precipitation can be offset simultaneously over either land or ocean. We also notice that the hydrological sensitivity (\% change in precipitation per unit change in temperature) is almost same over both land and ocean (Fig. 1b). Here, we have defined the hydrological sensitivity over land (ocean) as the ratio of change in land (ocean) averaged precipitation to change in land (ocean) averaged surface temperature.

We find that the prescribed aerosols with different latitudinal distributions along with doubled $\mathrm{CO}_{2}$ concentrations (geoengineering simulations) lead to different global mean forcings (Fig. 1c and d). Since there are linear relationships between the radiative forcing and the changes in global mean temperature (Fig. 1c) and between the temperature and precipitation changes (Fig. 1b), we find a linear relationship between the radiative forcing and the precipitation changes (Fig. 1d). The Polar geoengineering scenarios have positive residual radiative forcing while the Tropics scenarios have negative residual radiative forcing because the solar forcing is less effective over the poles relative to the tropics (Fig. 1c). This is further confirmed in Fig. 2 which shows that the Polar cases have smaller increase in the planetary albedo compared to the Tropics cases. The radiative forcing associated with planetary albedo changes drive the temperature changes. The Polar cases have lower albedo changes relative to the Uniform case and hence are warmer and wetter while opposite is true for Tropics cases. The variation of global mean surface temperature and precipitation with global mean radiative forcing (Fig. 1c and d) shows that as the maximum aerosol concentration over the poles increases (Polar1 to Polar6) the residual forcing increases and hence the global mean temperature and precipitation increase. Similarly, as the maximum aerosol concentration over the equator increases (Tropics1 to Tropics3), an opposite variation is noticed. In order to confirm that the global mean radiative forcing is sufficient to infer the global mean climate change we performed four additional geoengineering simulations with total amount of aerosols varied $(10,11,13$, and $14 \mathrm{Mt})$ for the Uniform distribution case. We find that the global mean temperature and precipitation changes follow the changes in global mean forcing (Fig. 3) for this set of simulations too.

To further investigate the degree of departure of the different geoengineering simulations from the control, we calculate the root mean square difference between the spatial patterns in geoengineered climates and the control climate and normalize this root mean square difference by the standard deviation of the control scenario (NRMSD). A value less than 1 for NRMSD would suggest that the geoengineered climate is indistinguishable from the control climate. Further, the geoengineering simulation with the smallest value for this quantity is the one that is closest to the control. In our study, we find that the NRMSD for temperature increases as the maximum concentration of aerosols at the poles increases and the NRMSD for precipitation increases as tropical maximum is increased (Fig. 4). When all grid points in the latitude-longitude domain are considered for computing the NRMSD (Fig. 4a), it shows large variations: 0.40 to 1.4 for surface temperature and 0.25 to 0.40 for precipitation. In the case of NRMSD calculated for zonal-mean profile (Fig. 4b), the spread is relatively less: 0.30 to 0.95 for surface temperature and 0.27 to 0.38 for precipitation. If the objective is to minimize the NRMSD in both temperature and precipitation simultaneously relative to the control case, the Uniform case is closest to the control case since it has the least distance from the origin in Fig. 4. Since the NRMSD for both temperature and precipitation are less than 2 standard deviations for all the geoengineering cases (Fig. 4), we conclude that these simulations are not significantly $(95 \%$ confidence level) different from the control.

\subsection{Spatial pattern of temperature and precipitation responses}

The change in zonal-mean surface temperature between the geoengineering cases and the control case $\left(1 \times \mathrm{CO}_{2}\right)$ show, similar to changes in global annual mean values, a monotonic increase at each latitude with increased polar 


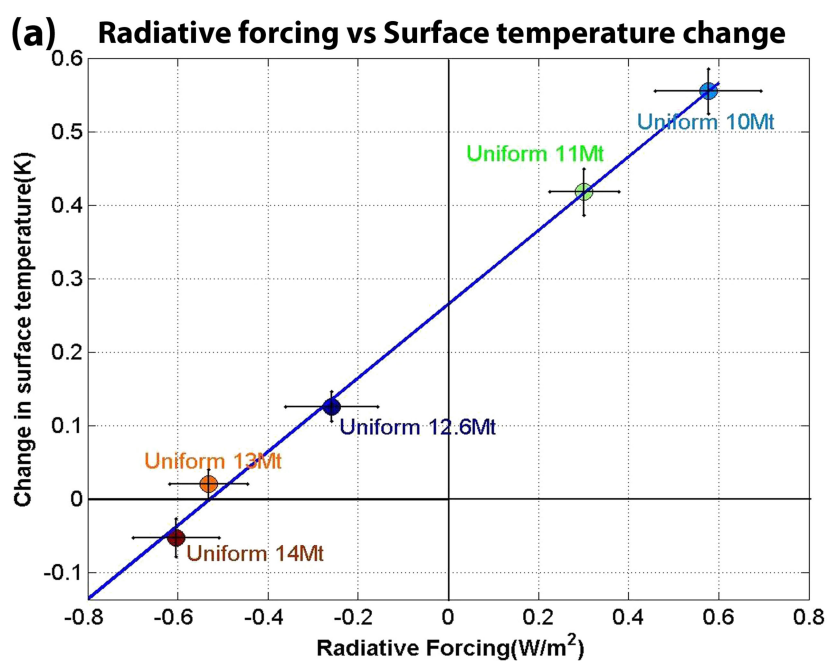

(b) Radiative forcing vs Precipitation change

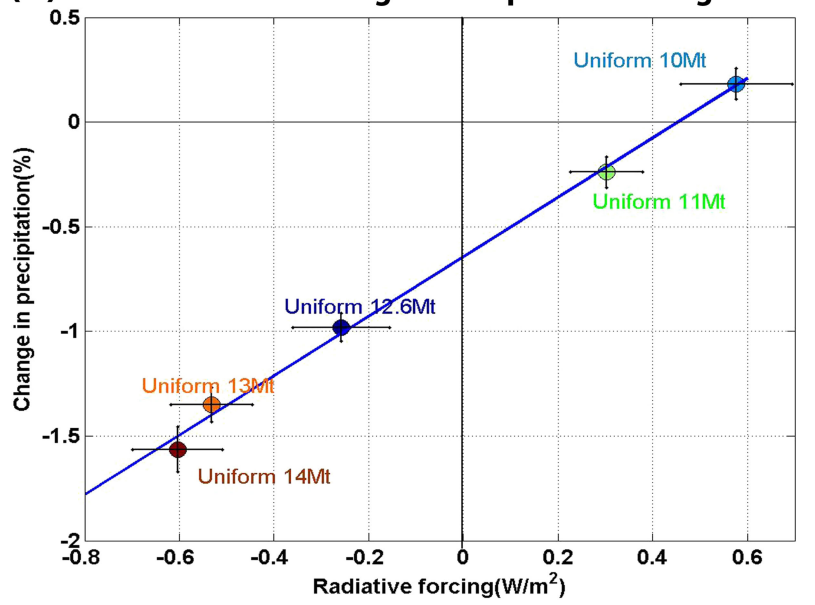

Figure 3. (a) Radiative forcing (RF) vs surface temperature change, (b) radiative forcing vs \% precipitation change for uniform distribution scenarios with $10 \mathrm{Mt}, 11 \mathrm{Mt}, 12.6 \mathrm{Mt}, 13 \mathrm{Mt}$ and $14 \mathrm{Mt}$. More aerosol mass leads to negative residual radiative forcing and hence cooler and drier climate, and smaller aerosol mass leads to positive residual radiative forcing and hence warmer and wetter climate. In (a) and (b) the horizontal and vertical bars represent the standard error of the respective variables. Results shown are averages of the last 20 years of 50-year SOM simulations for temperature and precipitation while the last 20 years of 40 -year fixed-SST simulations are used for radiative forcing calculations.

weighting (Fig. 5a). We notice a similar monotonic increase in zonal-mean land and zonal-mean ocean surface temperature (Fig. 6a and b). Further, we find that almost all geoengineering simulation show residual high latitude warming. In the Tropics cases, we find smaller residual warming in the high latitudes and cooler tropics. Similar to temperature changes, the change in zonal-mean precipitation between the geoengineering cases and the control case show a monotonic increase at each latitudes with increased polar weighting (Fig. 5b, 6c and d). We find large changes in precipitation
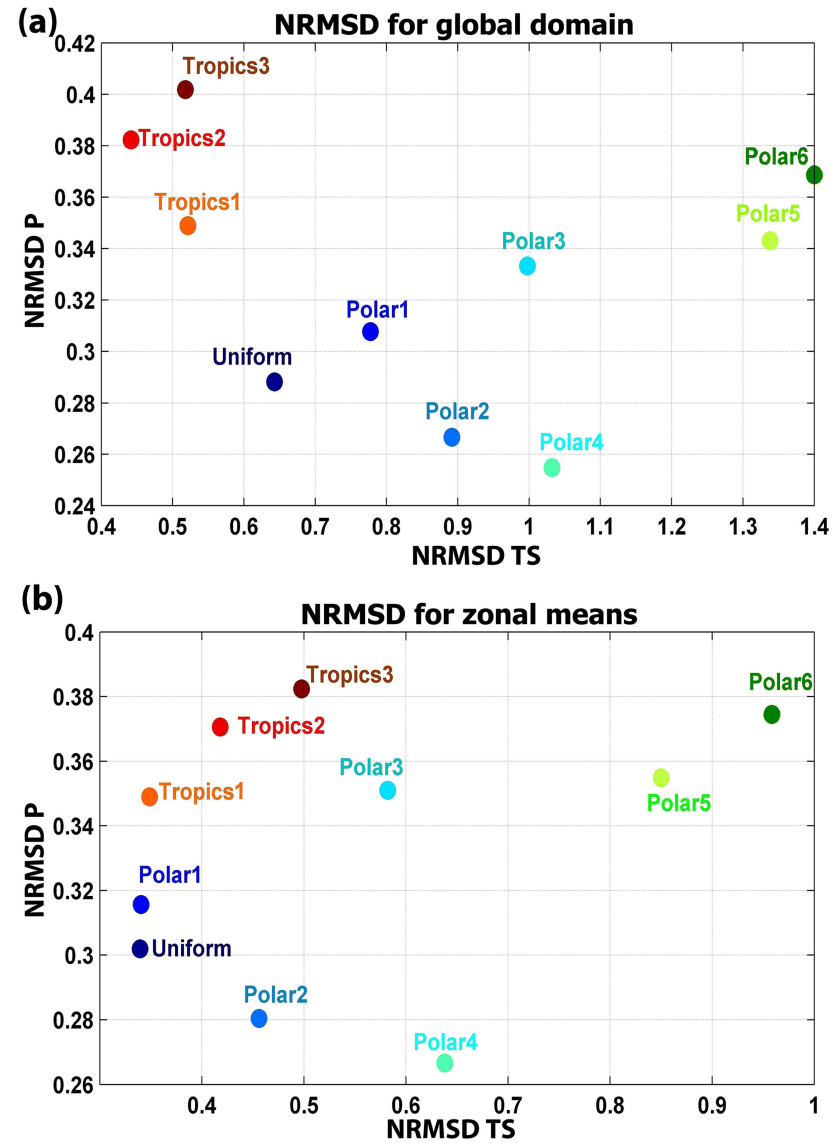

Figure 4. Normalized root mean square difference (NRMSD) of surface temperature and precipitation between geoengineering and control simulation normalized by respective standard deviations computed for the global domain (top panel) and for the zonal averages (bottom panel). The annual means of the last 30 years of the 60 -year control simulation are used to estimate the standard deviation. Simulation nearest to $\mathrm{x}$-axis represents the best precipitation mitigating scenario while the one closest to $y$-axis represents the best surface temperature mitigating scenario. Scenarios with maximum aerosol concentrations at the poles have larger NRMSD in temperature and conversely simulations with maximum at the equator have larger NRMSD in precipitation.

in the tropics which is likely to be seen as shifts in the intertropical convergence zone (ITCZ) but closer examination (Fig. 7) shows that the position of ITCZ remains the same in all the cases and the monotonic increase in precipitation with poleward weighting is clearly seen. Sharp gradients in precipitation response around the equator (region of ITCZ) are simulated in all our simulations. The sharp gradient in zonal mean precipitation response we simulate in the $2 \times \mathrm{CO}_{2}$ case in the tropics is similar to the near-term CMIP5 multi-model projections (Fig. 11.13a in IPCC, 2013). The precipitation response simulated over the high latitudes in $2 \times \mathrm{CO}_{2}$ case is also in agreement with the CMIP5 multi-model projections. In the case of the Tropics geoengineering simulations 


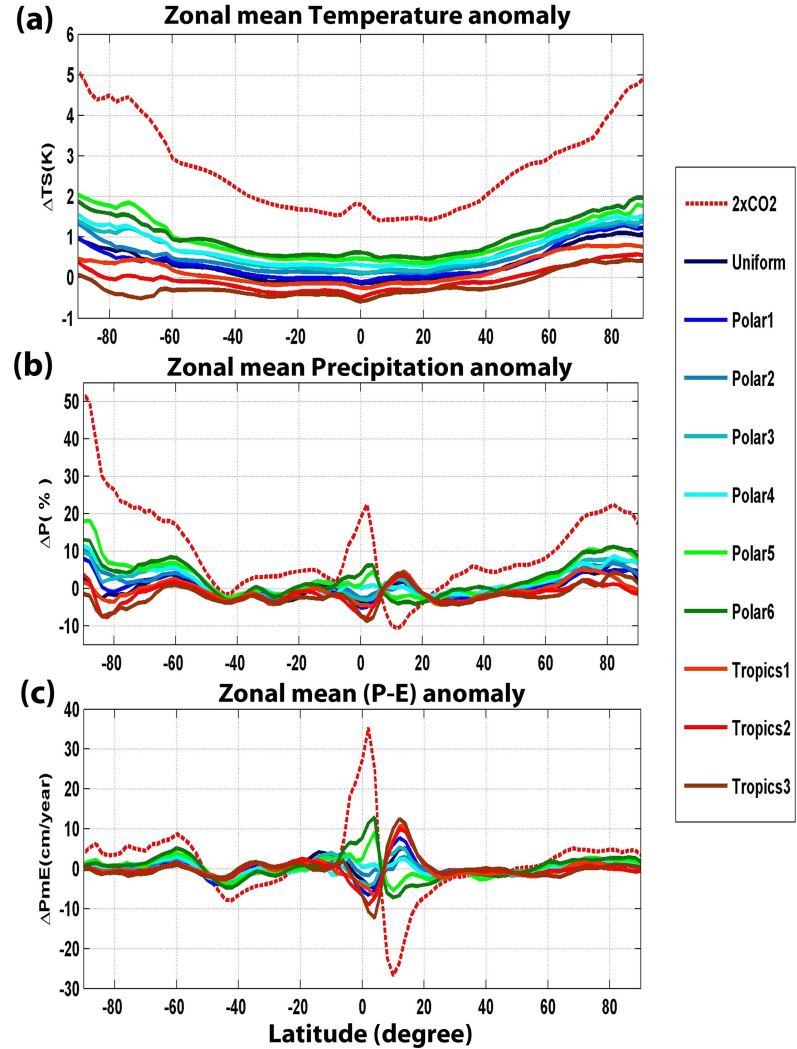

Figure 5. Zonal means of change in surface temperature $(\Delta T S)$, precipitation $(\Delta \mathrm{P})$ and precipitation minus evaporation $(\triangle \mathrm{PmE})$. (a) Zonal mean $\triangle \mathrm{TS}$ increases monotonically with increase in maximum concentrations over the poles and decreases with increase in tropical maxima. (b) Zonal mean $\Delta \mathrm{P}$ : polar maximum causes enhanced precipitation. (c) Zonal mean $\Delta \mathrm{PmE}$; polar maximum causes enhanced precipitation minus evaporation. Results shown are averages of the last 30 years of 60 -year simulations.

the precipitation response around the equator is exactly opposite to the response in $2 \times \mathrm{CO}_{2}$ case. This could be due to the overcooling of the tropics in the Tropics scenarios. However, the robust feature in the zonal-mean precipitation changes between the geoengineering cases and the control case is a monotonic increase at all latitudes when polar weighting is increased. This monotonicity is similar to the monotonicity seen in the global mean values. The changes in zonal mean precipitation minus evaporation (water budget) are similar to changes in zonal mean precipitation (Fig. 5c, 6e and f).

Figure 8 shows the spatial pattern of the radiative forcing in selected simulations: $2 \times \mathrm{CO}_{2}$, Uniform, Polar3, Tropics1, Polar6 and Tropics 3 cases. We notice that the radiative forcing in the $2 \times \mathrm{CO}_{2}$ case is significant over the whole globe but not significant in most regions in the geoengineering cases. The radiative forcing is positive in most locations in Polar cases. In the Tropics cases, the forcing is negative in the tropical regions and positive in the polar regions.
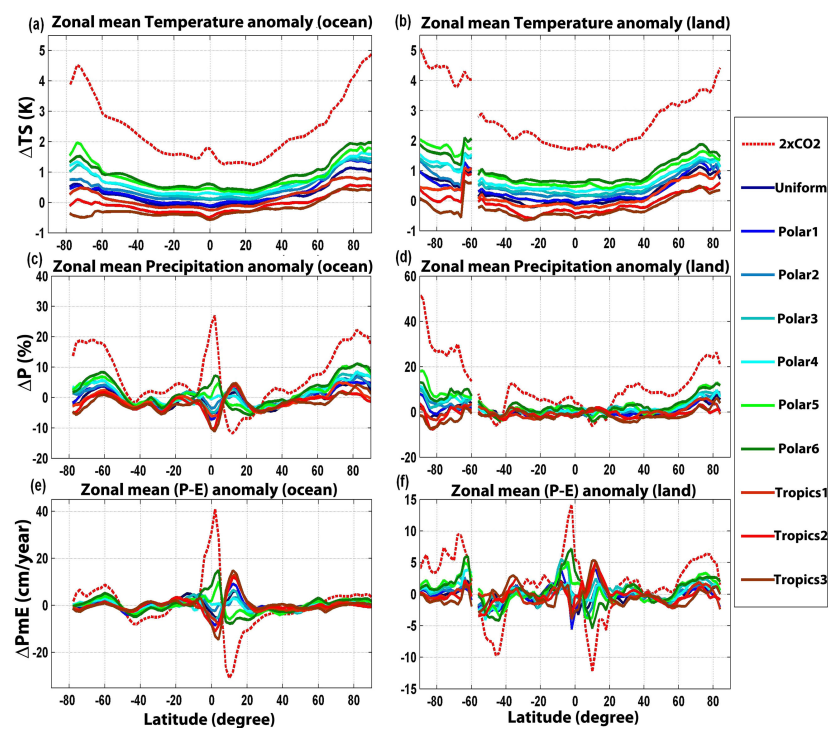

Figure 6. Changes in zonal mean surface temperature ( $\Delta \mathrm{TS})$, precipitation $(\Delta \mathrm{P})$ and precipitation minus evaporation $(\triangle \mathrm{PmE})$ over ocean (left panels) and land (right panels). (a) and (b): Zonal mean $\Delta \mathrm{TS}$ increases monotonically with increase in the magnitude of maximum concentration of aerosols over poles and decreases with increase in the magnitude of tropical maximum. (c) and (d): polar maximum causes enhanced precipitation. (e) and (f): polar maximum causes enhanced precipitation minus evaporation. Results shown are averages of the last 30 years of 60 -year simulations.

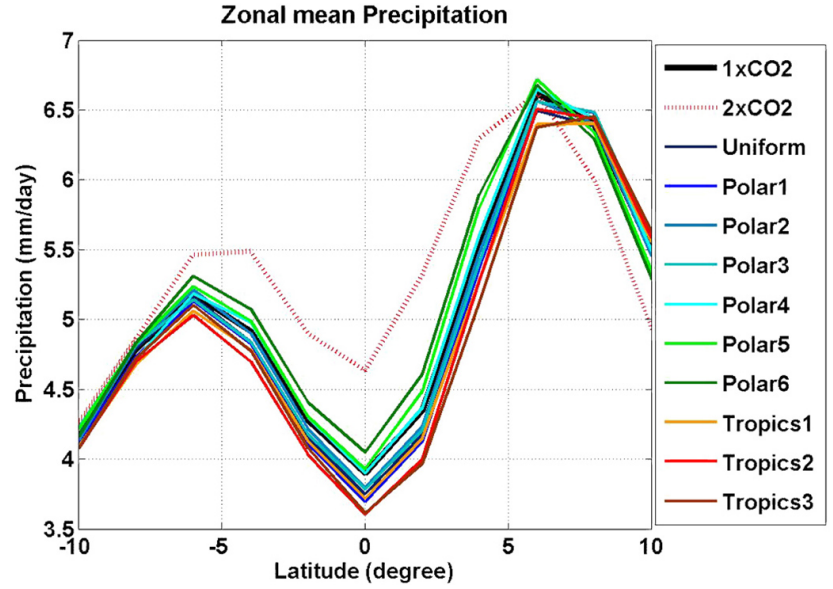

Figure 7. Zonal mean precipitation over the globe. The position of intertropical convergence zone (ITCZ) remains the same in all the geoengineering cases. The zonal mean precipitation decreases monotonically over the equator as the global mean radiative forcing increases. Results shown are averages of the last 30 years of 60-year simulations.

In the $2 \times \mathrm{CO}_{2}$ case, both temperature and precipitation changes are large and significant over the whole globe (Fig. 9). The temperature increase over poles is much larger than in the tropics, in agreement with previous studies (Caldeira and Wood, 2008; Lunt et al., 2008; Matthews and 

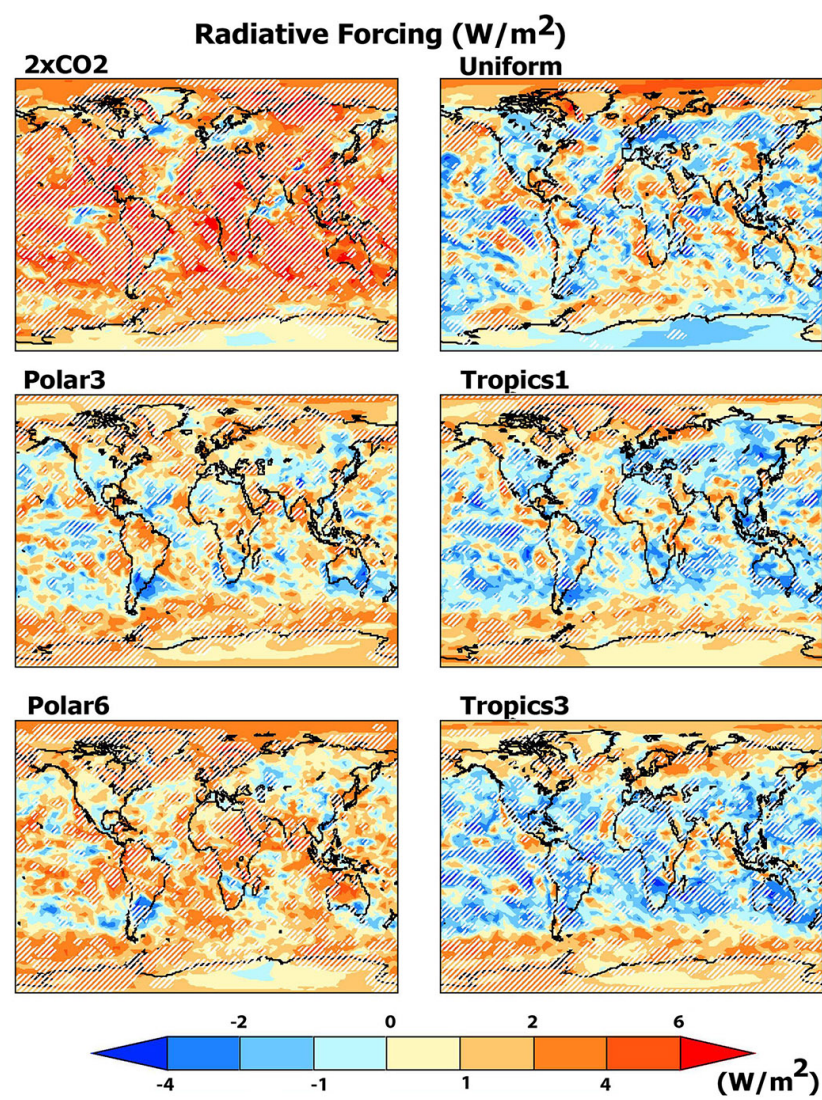

Figure 8. Spatial pattern of radiative forcing in the $2 \times \mathrm{CO}_{2}$, Uniform, and some polar and tropic geoengineering scenarios. In the Uniform and Tropics cases, there is a residual positive forcing in the high latitudes and negative forcing in the low latitudes indicating an inexact compensation. Hatching indicates the region where the changes are significant at $1 \%$ level. Significance level was estimated by Student's $t$ test. Results shown are averages of the last 20 years of 30-year simulations with fixed sea surface temperature and sea ice fraction.

Caldeira, 2007; Robock et al., 2008; Rasch et al., 2008b). The uniform geoengineering case (Uniform) shows mitigation in temperature with reduced precipitation relative to $1 \times \mathrm{CO}_{2}$. This is because of different fast precipitation response to $\mathrm{CO}_{2}$ forcing and solar forcing. In Polar3 case, the change in precipitation is largely offset but there is significant warming over large regions. However, temperature is largely offset in Tropics1 but there is decrease in precipitation relative to the uniform distribution case. The last four panels of Fig. 9 shows the extreme cases; the case with largest polar weighting (Polar6) significantly warms the planet while the case with largest tropical weighting (Tropics3) overcools the planet with large reduction in precipitation.
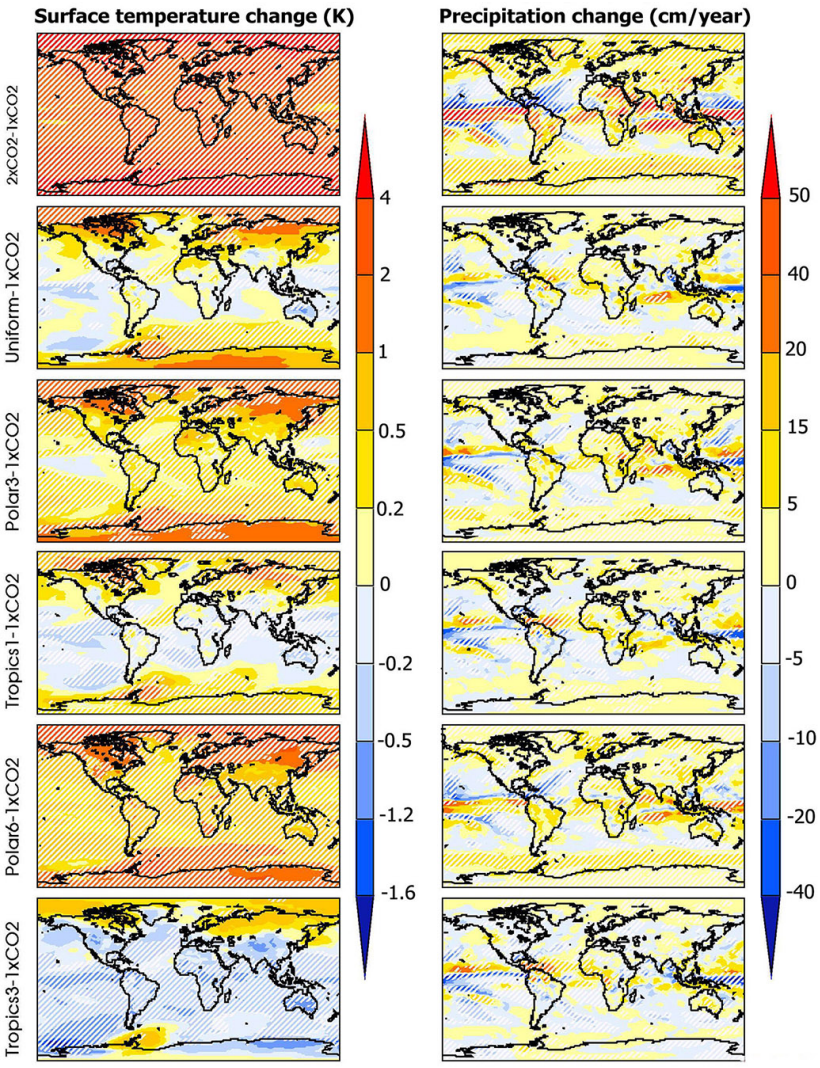

Figure 9. Changes in annual-mean surface temperature (left panels) and precipitation (right panels) in the $2 \times \mathrm{CO}_{2}$, Uniform, and some Polar and Tropics geoengineering scenarios relative to the control $\left(1 \times \mathrm{CO}_{2}\right)$. Hatching indicates the region where the changes are significant at $1 \%$ level. Significance level was estimated using Student's $t$ test. Both surface temperature and precipitation changes are large and significant everywhere in the $2 \times \mathrm{CO}_{2}$ and extreme scenarios (Polar6 and Tropics3). Although significant over large regions, both temperature and precipitation changes are small in the Uniform case. Polar3 scenario offsets global mean precipitation but not global mean temperature while Tropics 1 scenario offsets global mean temperature but with reduced precipitation. Results shown are averages of the last 30 years of 60 -year simulations.

\section{Discussion and conclusions}

In this study, for a fixed total amount of sulfate aerosols which when distributed uniformly nearly offsets the global mean temperature change from a doubling of $\mathrm{CO}_{2}$, there is a residual cooling when the aerosol concentration is maximized near the tropical regions and warming when concentration is maximized near the polar regions (Fig. 1c). Consequent changes in global mean precipitation are simulated as dictated by the hydrological sensitivity of the model (Fig. 1b). We also observe a similar monotonic increase in the precipitation intensity as the maximum aerosol concentration over the poles increases (Figs. 10, 11 and 12). The increases are of the order of $10 \%$ for low intensity (5th 


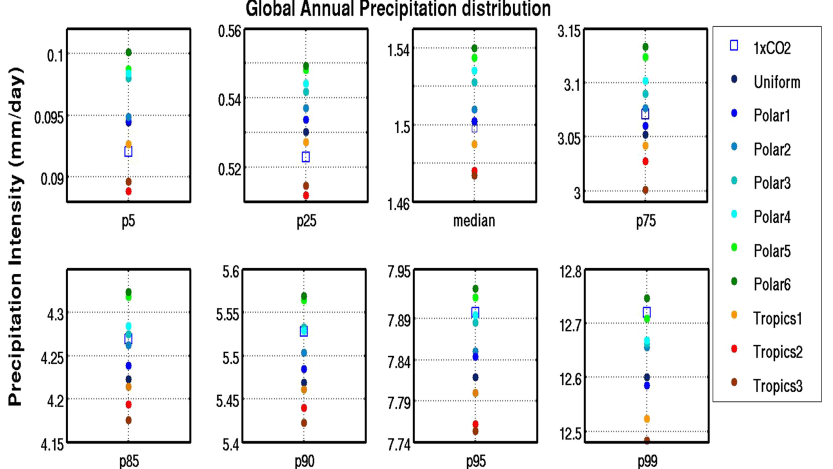

Figure 10. Percentile values (p5, p25, median, p75, p85, p90, p95 and p99) of precipitation intensity over Globe. There is a monotonic increase in precipitation for all percentile values as the maximum concentration of aerosols over poles increases. Grid-level monthly mean precipitation are used to calculate the percentile values. The last 30 years of 60 -year simulations are used for the statistics.

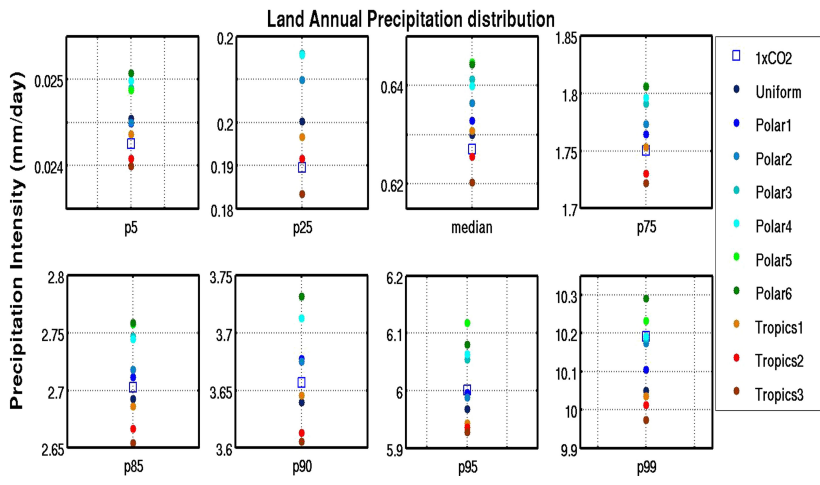

Figure 11. Percentile values (p5, p25, median, p75, p85, p90, p95 and p99) of precipitation intensity over Land. There is a monotonic increase in precipitation for all percentile values as the maximum concentration of aerosols over poles increases. Grid-level monthly mean precipitation over all land points are used to calculate the percentile values. The last 30 years of 60 -year simulations are used for the statistics.

percentile) and $2-3 \%$ for large intensity (99th percentile) between the extreme cases (Tropics3 and Polar6).

Our result that the global mean precipitation is reduced when aerosol concentration is maximized at the equator is in agreement with a recent study that shows a drastic reduction in tropical rainfall when aerosol concentration is maximum in the tropics (Ferraro et al. 2014). However, there are quantitative differences because the prescription of aerosols is different in the two studies. In Ferraro et al. (2014), the sulfate aerosols are prescribed approximately at $50 \mathrm{hPa}$ (lower stratosphere) while we prescribe them at TOM. Further, compared to our aerosol size (dry median radius $\approx 0.05 \mu \mathrm{m}$ ) the aerosol size used in Ferraro et al. (2014) is larger (dry median radius $\approx 0.1 \mu \mathrm{m}$ ).

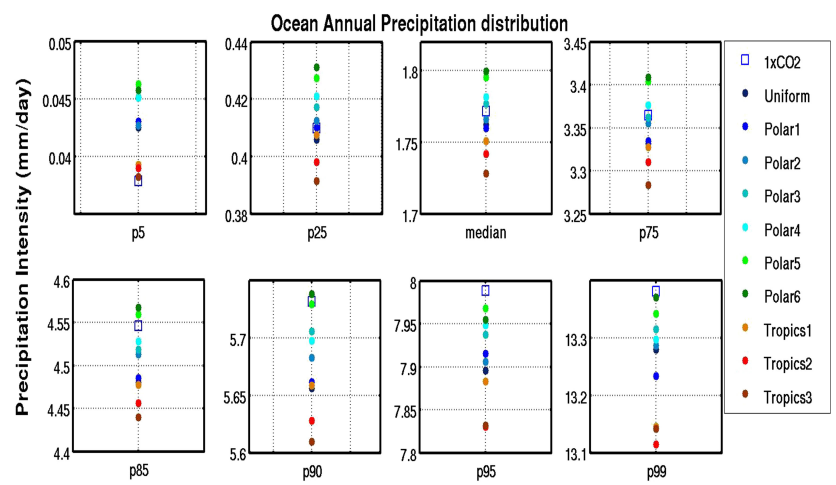

Figure 12. Percentile values (p5, p25, median, p75, p85, p90, p95 and p99) of precipitation intensity over Ocean. There is a monotonic increase in precipitation for all percentile values as the maximum concentration of aerosols over poles increases. Grid-level monthly mean precipitation over all ocean points are used to calculate the percentile values. The last 30 years of 60 -year simulations are used for the statistics.

In agreement with earlier studies (e.g., Bala et al., 2008), we find that both temperature and precipitation changes cannot be offset simultaneously. In agreement with this, not only in a simulation with uniform distribution but in all the geoengineering simulation with different latitudinal distribution (that is, even with non-uniform distribution of solar insolation reduction), we find that it is not possible to offset both temperature and precipitation changes simultaneously. The latitudinal distribution which offsets the warming leads to a drier climate while the distribution which offsets the precipitation results in a relatively warmer world (note that Bala et al. (2008) used a uniform solar insolation reduction). For a fixed total amount of aerosols but with different latitudinal distribution it is possible to achieve a range of global mean radiative forcing and thus a range of climate states.

Our findings should be viewed in the light of the limitations and uncertainties involved in this study. Our simulations are highly idealized as we have prescribed sulfate aerosol (to reduce the solar insolation) instead of injecting and transporting them. We have prescribed a fixed particle size distribution but particle size distribution would evolve with time and is shown to be important in precisely estimating the effects on different climate variables (Rasch et al., 2008b). Some modeling studies (Robock et al., 2008) have injected aerosol precursors into the stratosphere with fixed particle size distribution while other studies (Heckendorn et al., 2009; Pierce et al., 2010; Niemeier et al., 2010; Hommel and Graf, 2011; English et al., 2012) have demonstrated the importance of including the microphysics of particle growth. Further, we have focused our investigation primarily on global mean climate while several other studies (e.g., Robock et al., 2008; Irvine et al., 2010; Ricke et al., 2010) focused on regional disparities. 
In this study, we have not considered the consequences of detailed stratospheric dynamics and sulfate aerosol chemistry on the ozone layer (Tilmes et al., 2009). Thus our model does not account for the ozone loss that might take place due to the increased stratospheric sulfate aerosols. Our model lacks a dynamic ocean and sea ice components, and thus the effects of deep ocean circulation are not modeled here. Further, in this model an interactive land carbon cycle is not included and hence the impact of changes in the diffuse fraction of surface solar radiation due to stratospheric aerosols could not be investigated. We intend to use a later version of the model that includes carbon cycle to investigate the impacts of altered diffuse radiation in a future study. However, we believe our results on temperature and precipitation is so fundamental that they would be unchanged when additional components and feedbacks are included.

In summary, for a fixed total mass of aerosols, we find that the global mean climate is warmer and wetter when aerosol concentration is maximum over the poles relative to the uniform distribution case (which offsets global mean temperature change) because the global mean residual radiative forcing is positive in these cases when compared to the Uniform case. The opposite is true when aerosol concentration is maximum in the tropics. Further, our study clearly indicates that knowledge of the global mean radiative forcing, not the details of latitudinal distribution of aerosols, is sufficient to infer the global mean climate change.

Acknowledgements. Financial support for A. Modak was provided by the Divecha Centre for Climate Change, Indian Institute of Science. We thank the Supercomputer Education and Research Centre, Indian Institute of Science for providing the computational resources.

\section{Edited by: M. K. Dubey}

\section{References}

Allen, M. R. and Ingram, W. J.: Constraints on future changes in climate and the hydrologic cycle, Nature, 419, 224-232, doi:10.1038/nature01092, 2002.

Andrews, T., Forster, P. M., and Gregory, J. M.: A surface energy perspective on climate change, J. Climate., 22, 2557-2570, doi:10.1175/2008JCLI2759.1, 2009.

Bala, G., Caldeira, K., and Nemani, R.: Fast versus slow response in climate change: implications for the global hydrological cycle, Clim. Dynam. 35, 423-434, doi:10.1007/s00382-009-0583y, 2009.

Bala, G., Duffy P. B., and Taylor, K. E.: Impact of geoengineering schemes on the global hydrological cycle, P. Natl. Acad. Sci. USA, 105, 7664-7669, doi:10.1073/pnas.0711648105, 2008.

Ban-Weiss, G. A. and Calderia, K.: Geoengineering as an Optimization Problem, Environ. Res. Lett., 5, 034009, doi:10.1088/17489326/5/3/034009, 2010.

Betts, R. A., Boucher, O., Matthew, C., Cox, P. M., Falloon, P. D., Gedney, N., Hemming, D. L., Huntingford, C., Jones, C. D., Sex- ton, D. M. H., and Webb, M. J.: Projected increase in continental runoff due to plant responses to increasing carbon dioxide, Nature, 448, 1037-1041, doi:10.1038/nature06045, 2007.

Budyko, M. I.: The Earth's Climate Past and Future, Academic Press, 307 pp., 1982.

Caldeira, K. and Wood, L.: Global and Arctic climate engineering: Numerical model studies, Philos. T. Roy. Soc. A, 366, 40394056, doi:10.1098/rsta.2008.0132, 2008.

Cao, L., Bala, G., and Caldeira, K.: Climate response to changes in atmospheric carbon dioxide and solar irradiance on the time scale of days to weeks, Environ. Res. Lett., 7, 034015, doi:10.1088/1748-9326/7/3/034015, 2012.

Cao, L., Bala, G., Caldeira, K., Nemani, R., and Ban-Weiss, G. A.: Importance of carbon dioxide physiological forcing to future climate change, P. Natl. Acad. Sci. USA, doi:10.1073/pnas.0913000107, 2010.

Collins, W. D., Rasch, P. J., Boville, B. A., Hack, J. J., McCaa, J. R., Williamson, D. L., Kiehl, J. T., Briegleb, B., Bitz, C., Lin, S.-J., Zhang, M., and Dai, Y.: Description of the NCAR community atmosphere model (CAM 3.0) NCAR Tech. Rep. NCAR/TN464+STR National Center for Atmospheric Research, Boulder, CO, 226 pp., 2004.

Crutzen, P. J.: Albedo enhancement by stratospheric sulfur injections: A contribution to resolve a policy dilemma?, Clim. Change, 77, 211-220, doi:10.1007/s10584-006-9101-y, 2006.

Early, J. T.: Space-based solar shield to offset greenhouse effect, J. British Interplanetary Society, 42, 567-569, 1989.

English, J. M., Toon, O. B., and Mills, M. J.: Microphysical simulations of sulfur burdens from stratospheric sulfur geoengineering, Atmos. Chem. Phys., 12, 4775-4793, doi:10.5194/acp-12-47752012, 2012.

Ferraro, A. J., Highwood, E. J., and Charlton-Perez, A. J.: Weakened tropical circulation and reduced precipitation in response to geoengineering, Environ. Res. Lett., 9, 014001, doi:10.1088/1748-9326/9/1/014001, 2014.

Govindasamy, B. and Caldeira, K.: Geoengineering Earth's radiation balance to mitigate $\mathrm{CO}_{2}$-induced climate change, Geophys. Res. Lett., 27, 2141-2144, 2000.

Hansen, J., Sato, M., and Ruedy, R.: Radiative forcing and climate response J. Geophys. Res., 102, 6831-6864, 1997.

Heckendorn, P., Weisenstein, D., Fueglistaler, S., Luo, B. P., Rozanov, E., Schraner, M., Thomason, L. W., and Peter, T.: The impact of geoengineering aerosols on stratospheric temperature and ozone, Environ. Res. Lett., 4, 045108, doi:10.1088/17489326/4/4/045108, 2009.

Hommel, R. and Graf, H. F.: Modelling the size distribution of geoengineered stratospheric aerosols, Atmos. Sci. Lett., 12, 168175, doi:10.1002/asl.285, 2011.

Irvine, P. J., Ridgwell, A., and Lunt, D. J.: Assessing the regional disparities in geoengineering impacts, Geophys. Res. Lett., 37, L18702, doi:10.1029/2010GL044447, 2010.

IPCC 2007 Climate Change: The Physical Science Basis Contribution of Working Group 1 to the Fourth Assessment Report of the Intergovernmental Panel on Climate Change, edited by: Solomon, S., Qin, D., Manning, M., Chen, Z., Marquis, M., Averyt, K. B., Tignor, M., and Miller, H. L., Cambridge, UK and New York, USA, Cambridge University Press, 996 pp., 2007.

IPCC 2013 Climate Change: The Physical Science Basis. Contribution of Working Group 1 to the Fifth Assessment Report of the 
Intergovernmental Panel on Climate Change, edited by: Stocker, T. F., Qin, D., Plattner, G. K., Tignor, M., Allen, S. K., Boschung, J., Nauels, A., Xia, Y., Bex, V., and Midgley, P. M., Cambridge University Press, Cambridge, UK and New York, NY, USA, 1535 pp., 2013.

Jones, A., Haywood, J., Boucher, O., Kravitz, B., and Robock, A.: Geoengineering by stratospheric $\mathrm{SO}_{2}$ injection: results from the Met Office HadGEM2 climate model and comparison with the Goddard Institute for Space Studies ModelE, Atmos. Chem. Phys., 10, 5999-6006, doi:10.5194/acp-10-5999-2010, 2010.

Keith, D. W.: Geoengineering the climate: history and prospect, Annu. Rev. Energ. Env., 25, 245-284, 2000.

Lunt, D. J., Ridgwell, A., Valdes, P. J., and Seale, A.: Sunshade world: a fully coupled GCM evaluation of the climatic impacts of geoengineering, Geophys. Res. Lett., 35, L12710, doi:10.1029/2008GL033674, 2008.

Matthews, H. D. and Caldeira, K.: Transient climate-carbon simulations of planetary geoengineering, P. Natl Acad. Sci. USA, 104, 9949-9954, doi:10.1073/pnas.0700419104, 2007.

MacMartin, D. G., Keith, D. W., Kravitz, B., and Caldeira, K.: Management of trade-offs in geoengineering through optimal choice of non-uniform radiative forcing, Nature Clim. Change, 3, 365368, doi:10.1038/nclimate1722, 2012.

McCormick, M. P.,Thomason, L. W., and Trepte, C. R.: Atmospheric effects of the Mt. Pinatubo eruption, Nature, 373, 399404, 1995.

Niemeier, U., Schmidt, H., and Timmreck, C.: The dependency of geoengineered sulfate aerosol on the emission strategy, Atmos. Sci. Lett., 12, 189-194, doi: 10.1002/asl.304, 2010.

Parker, D. E., Wilson, H., Jones, P. D., Christy, J. R., and Folland C. K.: The impact of Mount Pinatubo on worldwide temperatures, Int. J. Climatol., 16, 487-497, 1996.

Pierce, J. R., Weisenstein, D. K., Heckendorn, P., Peter, T., and Keith, D. W.: Efficient formation of stratospheric aerosol for climate engineering by emission of condensible vapor from aircraft, Geophys. Res. Lett., 37, L18805, doi:10.1029/2010GL043975, 2010.

Rasch, P. J., Tilmes, S., Turco, R. P., Robock, A., Oman, L., Chen, C. C., Stenchikov, G. L., and Garcia, R. R.: An overview of geoengineering of climate using stratospheric sulphateaerosols, Philos. T. Roy. Soc. A, 366, 4007-4037, doi:10.1098/rsta.2008.0131, 2008a.
Rasch, P. J., Crutzen, P. J., and Coleman, D. B.: Exploring the geoengineering of climate using stratospheric sulfate aerosols: The role of particle size, Geophys. Res. Lett., 35, L02809, doi:10.1029/2007GL032179, 2008b.

Robock, A., Oman, L., and Stenchikov, G. L.: Regional climate responses to geoengineering with tropical and Arctic SO2 injections, J. Geophys. Res., 113, D16101, doi:10.1029/2008JD010050, 2008.

Ricke, K. L., Morgan, M. G., and Allen, M. R.: Regional climate response to solar-radiation management, Nature Geosci., 3, 537541, 2010.

Shepherd, J., Caldeira, K., Cox, P., Haigh, J., Keith, D., Launder, B., Mace, G., MacKerron, G., Pyle, J., Rayner, S., Redgwell, C., and Watson, A.: Geoengineering the climate: science, governance and uncertainty, report, The Royal Society, London, 2009.

Tilmes, S., Garcia, R. R., Kinnison, D. E., Gettelman, A., and Rasch, P. J.: Impact of geoengineered aerosols on the troposphere and stratosphere, J. Geophys. Res., 114, D12305, doi:10.1029/2008JD011420, 2009.

Tilmes, S., Fasullo, J., Lamarque, J., F., Marsh, D., R., Ills, M., Alterskjær, K., Muri, H., Kristjánsson, J., E., Boucher, O., Schulz, M., Cole, J., N., S., Curry, C., L., Jones, A., Haywood, J., Irvine, P., J., Ji, D., Moore, J., C., Karam, D., B., Kravitz, B., Rasch, P., J., Singh, B., Yoon, J., H., Niemeier, U., Schmidt, H., Robock, A., Yang, S., and Watanabe, S.: The hydrological impact of geoengineering in the Geoengineering Model Intercomparison Project (GeoMIP), J. Geophys. Res. Atmos., 118, 11036-11058, doi:10.1002/jgrd.50868, 2013.

Trenberth, K. E. and Dai, A.: Effects of Mount Pinatubo volcanic eruption on the hydrological cycle as an ana$\log$ of geoengineering, Geophys. Res. Lett., 34, L15702, doi:10.1029/2007GL030524, 2007.

Wigley, T. M. L.: A combined mitigation/geoengineering approach to climate stabilization, Science, 314, 452-454, doi:10.1126/science.1131728, 2006. 